La revue La revue pour l'histoire du CNRS

$9 \mid 2003$

Histoire du temps présent

\title{
La raison malmenée. De l'origine des idées reçues en biologie moderne
}

Gérard Nissim Amzallag. Préface d'André Pichot. CNRS ÉDITIONS, Paris, 2002

\section{Girolamo Ramunni}

\section{(2) OpenEdition}

\section{Journals}

Édition électronique

URL : https://journals.openedition.org/histoire-cnrs/421

DOI : $10.4000 /$ histoire-cnrs.421

ISSN : 1955-2408

Éditeur

CNRS Éditions

\section{Édition imprimée}

Date de publication : 5 novembre 2003

ISBN : 978-2-271-06144-7

ISSN : $1298-9800$

\section{Référence électronique}

Girolamo Ramunni, «La raison malmenée. De l'origine des idées reçues en biologie moderne », La revue pour l'histoire du CNRS [En ligne], 9 | 2003, mis en ligne le 07 mars 2006, consulté le 20 mai 2021. URL : http://journals.openedition.org/histoire-cnrs/421 ; DOI : https://doi.org/10.4000/histoire-cnrs. 421

Ce document a été généré automatiquement le 20 mai 2021.

Comité pour l'histoire du CNRS 


\section{La raison malmenée. De l'origine des idées reçues en biologie moderne}

Gérard Nissim Amzallag. Préface d'André Pichot. CNRS ÉDITIONS, Paris, 2002

\section{Girolamo Ramunni}

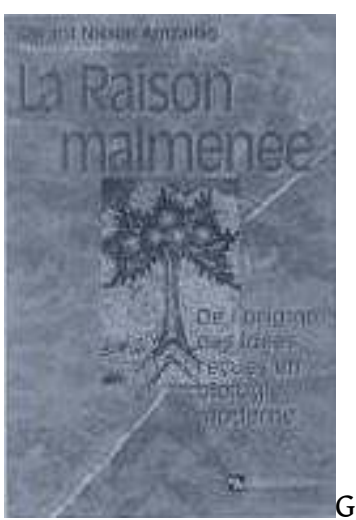

Gérard Nissim Amzallag, professeur à l'université hébraïque de Jérusalem, présente une thèse forte : une nouvelle épistémologie qui, prenant appui sur les problèmes que soulèvent les sciences du vivant, crée un monde du savoir nouveau fondé sur la séparation entre sciences et technologie, considérant celle-ci comme «fondamentalement distincte de la connaissance, voire (opposée) intellectuellement. Un monde où il est ouvertement affirmé que, s'il n'y a de technique que du général, il n'y a de science que de l'individu. » L'auteur fait la démonstration de la nécessité de cette rupture à venir s'appuyant sur les travaux d'historiens et, naturellement, de scientifiques.

1 Sa thèse le conduit à une relecture de l'histoire des sciences, depuis la révolution scientifique. Il veut faire la démonstration que le développement qu'a connu la science est due aux alliances que les scientifiques ont su établir avec le pouvoir politique, ou d'autres groupes de pouvoirs au sein des sociétés. Ce qui expliquerait que la physique se soit développée avant la biologie, car intéressant les princes et les rois par les machines 
qu'elle pouvait construire. Le même paradigme sert à expliquer le système de « reproduction » au sein de la communauté scientifique. L'auteur reproduit un très joli passage tiré du Nouveau système de physiologie végétale de François-Vincent Raspail (1837) : « Après avoir intrigué pour soi, on intrigue d'abord pour ses enfants... puis pour les gendres, puis pour leurs enfants au berceau. " Sa thèse le conduit à analyser l'attitude des scientifiques vis à vis de la fraude. Dans certains cas de fraude, l'indulgence l'emporte, alors que dans d'autres situations, on se sert de la fraude pour discréditer la théorie adverse, sans avoir les preuves qui permettent d'étayer la sienne. En mettant en parallèle l'eugénisme et le lyssenkisme, l'auteur veut montrer, par une analyse détaillée de l'histoire de l'opposition entre eugénistes et lyssenkistes, que Trofim Denissovitch Lyssenko a été une occasion habilement exploitée par les eugénistes pour imposer la valeur de leurs idées. Une remarque s'impose : l'auteur semble parfois assimiler eugénisme et racisme, qui, comme on le sait depuis les travaux des sociologues et des historiens, ne peuvent pas être confondus. Ce qui n'empêche que l'on puisse être eugéniste et raciste. Cette partie sur les fraudes est intéressante car l'auteur s'efforce d'en faire une taxonomie, montrant par là l'étendue et la diversité des modalités de fabrication de données pour étayer sa thèse.

$2 \mathrm{Au}$ fond de ces comportements déviants, on trouve le paradigme dominant d'une science déterministe. C'est là la conclusion de l'auteur. Ce paradigme serait si puissant qu'il conduirait même des scientifiques éminents, tel Einstein, à faire des affirmations qui, soustraites au contexte polémique dans lequel elles ont été formulées, semblent plutôt relever d'un attachement entêté pour son point de vue que de la critique ouverte des conceptions que l'on défend. Or, cela a conduit à privilégier en biologie l'aspect réductionniste, surtout parce que l'idéal de scientificité avait été construit à partir de la physique. Or, la biologie se situe au cœur des autres sciences, en liens avec les sciences physiques et les sciences humaines. C'est pourquoi elle pourrait permettre l'émergence d'un cadre épistémologique "dans lequel les cas de figure ignorés par l'approche déterministe sont envisageables...». Un programme ambitieux qui se propose de provoquer, dans la conception et la pratique de la science, un changement radical, équivalent à celui né avec la première révolution scientifique. C'est un vœu tentant pour lequel il faudra fermement batailler car il n'est pas simple de renverser les idées dominantes qui de surcroît rencontrent le succès.

INDEX

Mots-clés : biologie, raison, moderne

\section{AUTEUR}

GIROLAMO RAMUNNI

Professeur à l'université Lyon II 